\title{
A Time-Comparison Circuit in the Electric Fish Midbrain. I. Behavior and Physiology
}

\author{
Catherine E. Carr, ${ }^{1}$ Walter Heiligenberg, and Gary J. Rose \\ Neurobiology Unit, Scripps Institution of Oceanography, University of California at San Diego, La Jolla, \\ California 92093
}

\begin{abstract}
Behavioral experiments show that the weakly electric fish, $E i$ genmannia, detects differences in timing as small as $400 \mathrm{nsec}$ between electric signals from different parts of its body surface. The neural basis of this remarkable temporal resolution was investigated by recording from elements of the phase-coding system, a chain of electrotonically connected neurons devoted to the processing of temporal information. Each element of this system fires a single action potential for every cycle of the electric signal (either the fish's own electric organ discharge or a sinusoidal signal of similar frequency). For phase-coding primary afferents and midbrain neurons, the temporal resolution was determined by measuring each unit's capacity to lock its spike to a particular phase of the stimulus cycle. The jitter of a neuron's response (measured as the standard deviation of the timing of the spikes with respect to the stimulus) decreases from the level of the primary afferent (mean $=30 \mu \mathrm{sec}$ ) to the midbrain torus (mean $=11 \mu \mathrm{sec}$ ); these results can be correlated with morphological measures of convergence. The temporal resolution of single neurons is still inferior to that displayed at the behavioral level.
\end{abstract}

The detection of small temporal disparities between two signals is a process of general interest in sensory physiology, mediating localization of sound in the auditory system and providing an illusion of depth perception in vision (Pulfrich phenomenon). We employ a behavioral assay, the Jamming Avoidance Response (JAR), to demonstrate that the weakly electric fish, $\mathrm{Ei}$ genmannia, is able to detect temporal disparities of electrical signals as small as $400 \mathrm{nsec}$. In order to understand the origins of this sensitivity, we used intracellular recording techniques to identify the individual elements of the underlying neuronal circuit with respect to their response properties and morphology. In a subsequent study (Carr et al., in press), ultrastructural techniques have been used to reconstruct the midbrain circuit that performs these time comparisons.

Eigenmannia is a South American gymnotiform fish which produces a high-frequency wave-type electric organ discharge. It uses this discharge both for electrolocation and for social communication. These fish possess a simple behavior, the JAR, whereby they shift the frequency of their electric organ discharge so as to avoid being jammed by a neighboring conspecific with a similar frequency (usually within $+/-20 \mathrm{~Hz}$; Bullock et al.,

Received Feb. 11, 1985; revised July 9, 1985; accepted July 10, 1985.

We gratefully acknowledge the advice of Leonard Maler, John Dye, James Enright, Theodore Bullock, Masakazu Konishi, Clifford Keller, Randy Zelick, Susan Volman, Herman Wagner, and an anonymous referee. This work was supported by NSF Grant BNS76-20761 to W.H.; postdoctoral fellowship Grant NS07261-02 to G.J.R.; and a Harry Crossley Bursary to C.E.C.

${ }^{1}$ Present address: Department of Biology, California Institute of Technology, Pasadena, CA 91125.

Copyright (C) 1986 Society for Neuroscience $0270-6474 / 86 / 010107-13 \$ 02.00 / 0$
1972). Since Eigenmannia lowers its frequency if its neighbor's frequency is slightly higher, and raises its frequency if its neighbor's is slightly lower, it must be able to detect the sign of the frequency difference. This detection is accomplished by simultaneous evaluation of modulations in the amplitude and in the timing of zero-crossings, or phase, of the nearly sinusoidal signal resulting from the interference of the two electric organ discharges (Heiligenberg et al., 1978; Fig. 1). (Zero-crossing is the time at which the voltage difference across the skin changes from inside-positive to outside-positive.) The JAR is an ideal system in which to identify the smallest detectable timing differences, as it is readily quantifiable, does not habituate, and persists in neurophysiological preparations.

When two electric organ discharge signals of similar frequency add in the water, they form a quasisinusoidal signal whose instantaneous amplitude and phase are modulated ("beat") at a rate equal to the frequency difference between the two signals (Fig. 1). Behavioral analyses have shown that the fish uses modulations of amplitude and of differential phase (the difference in timing of the signal at different regions of the body surface) to determine whether its neighbor's signal is higher or lower in frequency than its own (Heiligenberg and Bastian, 1980; Heiligenberg and Partridge, 1981; Heiligenberg et al., 1978). The evaluation of temporal disparities requires that the fish compare areas of its body surface in which its own signal, $\mathrm{S} 1$, is differentially contaminated by the interfering signal, $\mathrm{S} 2$. For relatively small amplitudes of the interfering $S 2$ signal, the depth of the phase modulation, measured in radians, is equal to the amplitude ratio $|S 2| /|S 1|$. If the signal from an area of the body with a sizable $|\mathrm{S} 2| /|\mathrm{S} 1|$ ratio is compared to the signal in an area of the body less contaminated by the interfering signal, $\mathrm{S} 2$, a local increase in amplitude will be accompanied by a phase lag and a decrease in amplitude will be accompanied by a phase lead when the S2 frequency is higher than that of the S1 (Fig. $1, B$ and $C$, left). When the $\mathbf{S} 2$ signal is lower in frequency, the opposite relationship between phase and amplitude is obtained (Fig. 1, $B$ and $C$, right). A simultaneous evaluation of phase and amplitude modulations therefore allows the fish to compute whether the interfering signal is higher or lower in frequency than its own signal and thus to change the frequency of its electric organ discharge.

Eigenmannia evaluates changes in phase and amplitude information via an array of electroreceptors distributed over the body surface. Phase- and amplitude-sensitive receptors are innervated by phase- and amplitude-sensitive primary afferents, respectively (Scheich et al., 1973). Phase-coding afferents fire in response to every clectric organ discharge cycle, phase-locking to the zero-crossing of the signal, and the timing of the spike thus follows the temporal modulation in phase produced by the addition of the contaminating signal from the second fish (Fig. 1C). These primary afferents project somatotopically to different laminae of the electrosensory lateral line lobe (ELL) in the me- 
A $\Delta F=$ frequency of $S 2$ - frequency of $S 1$
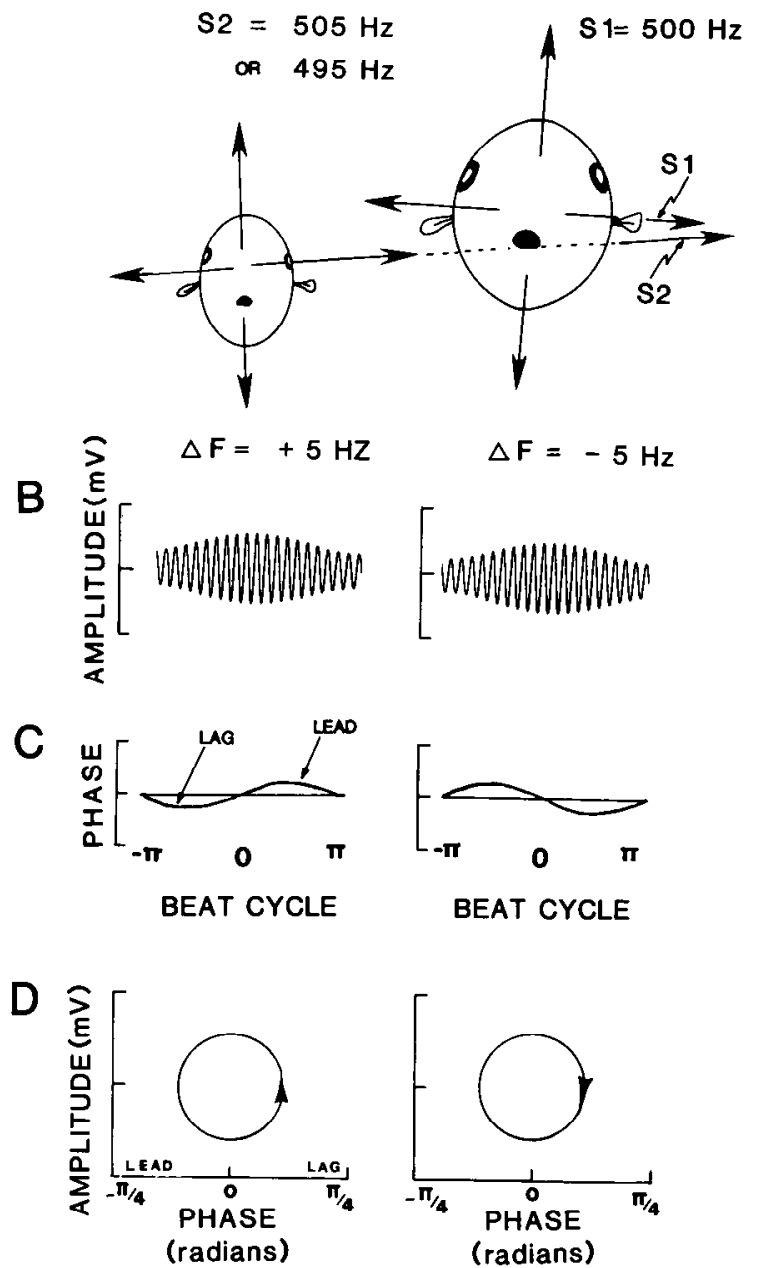

Figure 1. Phase and amplitude modulations of a fish's electric organ discharge upon contamination by a neighbor's signal of higher or lower frequency than its own (adapted from Bastian and Heiligenberg, 1980a; see Heiligenberg et al., 1978 for further details). $A$, Diagram of currentflow patterns resulting from the internally generated electric organ discharge (S1) of the subject fish on the right, and the transversely oriented signal of a neighbor's electric organ discharge (S2). $B$. The fish must be able to detect whether its neighbor's electric organ discharge (S2) is higher or lower in frequency than its own signal, so that it can lower or raise its own electric organ discharge frequency, and thus avoid being jammed. The two situations shown are a higher-frequency S2 $(505 \mathrm{~Hz})$ on the left, and a lower-frequency S2 $(495 \mathrm{~Hz})$ on the right. The two signals beat at a rate equal to the difference in their frequencies. It is shown that the resulting amplitude modulations are equal whether the neighbor's signal (S2) is higher or lower than the S1. C, Plots of the phase of the contaminated signal relative to the uncontaminated $S 1$ (straight line) are opposite for the two cases. This provides information as to whether the neighboring fish is higher or lower in frequency when combined with amplitude information. The depth of the phase modulation depends upon the strength of the neighbor's signal (S2). $D$, Lissajous-like figure of changes in amplitude plotted against phase (equivalent to temporal modulations) in a state plane. The graph is circular for low amplitudes of $\mathbf{S} 2$ and shows an anticlockwise rotation when the $S 2$ is higher in frequency than the $S 1$, and a clockwise rotation if the $S 2$ is lower in frequency. The temporal equivalent of $\pi / 2$ depends upon the frequency of the fish, being $0.5 \mathrm{mscc}$ for a fish with a $500 \mathrm{~Hz}$ electric organ discharge. $\Delta F=$ difference in frequency between neighbor (S2) and subject fish (S1). dulla (Carr et al., 1982; Heiligenberg and Dye, 1982; Maler, 1979; Maler et al., 1974). Phase-coding afferents form characteristic gap-junction synapses upon spherical cells, which project directly to lamina VI of the midbrain torus semicircularis pars dorsalis (torus), a midbrain sensory nucleus similar to the inferior colliculus. Amplitude-coding cells of the electrosensory lateral line lobe project to the laminae above and below lamina VI (Carr et al., 1981; Maler et al., 1982; Shumway, 1984).

Anatomical studies have shown that timing comparisons are likely to occur in the torus, as phase channels are segregated up to this level (see Fig. 5) and phase-coding input terminates in lamina VI, which contains no efferent cells. The only outputs from lamina VI are (1) the thin local axons of the small cells of lamina VI, which travel towards laminae V and VII, and (2) the cells of laminae V and VII, which send their dendrites into lamina VI (Carr and Maler, 1985; Heiligenberg and Carr, 1983; Rose and Heiligenberg, 1985). From these data it was predicted that the phase comparisons were performed in and around lamina VI (Carr and Heiligenberg, 1982; Carr et al., 1981; Carr et al., 1983). Recent intracellular analyses have confirmed that the small cells of lamina VI respond to specific temporal disparities. In addition, several other phase-related cell types in the torus have been identified (Bastian and Heiligenberg, 1980a, b; Heiligenberg and Carr, 1983; Heiligenberg and Rose, 1985). Still other cell types appear to have combined both phase and amplitude information (Heiligenberg and Rose, 1985; Partridge et al., 1981).

How accurate is this phase comparison system? The original observations of Bullock et al. (1972) showed that Eigenmannia will perform a JAR even if the jamming stimulus is on the order of $1000 \times$ weaker than the animal's own electric organ discharge. In view of the more recent discovery that the JAR requires evaluation of differential phase, we deduced from Bullock et al.'s original observation that Eigenmannia might be capable of discriminating temporal disparities in the microsecond range (see Fig. 2). The experimental paradigm used by those authors, however, did not allow an exact measurement of the intensity ratio of the stimulus perceived by the animal's receptors, as the natural electric organ discharge of the uncurarized animal was used, rather than an experimentally controlled stimulus. The paradigm presented in this paper allows an exact calculation of threshold intensity values between the stimuli, $S 1$ and $S 2$, and, hence, of the minimal temporal disparities necessary for the JAR, which we show to be in the region of 400 nsec.

\section{Materials and Methods}

All experiments were performed upon Eigenmannia spp., $10-14 \mathrm{~cm}$ long, which were immobilized by intramuscular injections of $0.02 \mathrm{ml}$ of $1-2 \%$ Flaxedil (Davis-Geck) and then suspended under the water surface. The fish were ventilated by a constant flow of water through the mouth. Any surgery was performed after topical application of a local anesthetic, $2 \%$ lidocaine (Xylocaine). Although the fish's electric organ discharge was silenced by Flaxedil, which acts at the spinal electromotoneuron-electrocyte level, the JAR could still be elicited. It was measured by placing a suction electrode over the fish's tail (Fig. 2) to record the spinal volley associated with the pacemaker activity.

The tish's electric organ discharge was replaced by a sine wave stimulus that was similar in frequency and amplitude. This stimulus mimics the fish's electric organ discharge and is termed S1. A second stimulus of slightly different frequency was used to mimic the signal of a neighboring conspecific. This signal was termed S2, and was delivered either through the same set of electrodes as the $S 1$, or through any two of an array of electrodes surrounding the fish.

\section{Behavior}

The behavioral experiments were designed to test the limits of the fish's ability to detect small temporal disparities. The experimental regimens are diagrammed in Figure 2. The procedures follow those in Heiligenberg et al. (1978) and Heiligenberg and Bastian (1980). 
Heiligenberg et al. (1978) demonstrated that the JAR may be driven by pairwise interactions of areas of the body surface where S1 is differentially contaminated by the interfering signal, $\mathrm{S} 2$. This is achieved in nature by the different geometry of a fish's own signal and that of its neighbor. The fish's own electric organ discharge, due to its internal current source, recruits all receptors on the body surface, while the neighbor's electric organ discharge affects only receptors, in proportion to the local current component that is vertically oriented to the fish's body surface.

The experimental paradigm in Figure 2 was designed to test the minimum contamination needed to drive the JAR. Two major requirements were that (1) some areas of the body surface must be stimulated with different $|\mathbf{S} 2| /|\mathrm{S} 1|$ ratios, to produce the necessary differential contamination, and (2) the precise amplitude ratio between $S 2$ and $S 1$ must be known, so as to permit calculation of the temporal disparities produced by the addition of $\mathbf{S} 1$ and $\mathbf{S} 2$. These requirements were fulfilled by placing the fish in a chamber divided into two compartments. With this arrangement, different $|\mathbf{S} 2| /|\mathrm{S} 1|$ mixtures could be administered to each compartment. Delivering the mixed signal through the same electrodes cnabled us to determine the precise $|\mathrm{S} 2| /|\mathrm{S} 1|$ ratio experienced by electroreceptors. (Note that the local $|\mathbf{S} 2| /|\mathbf{S} 1|$ ratio is very difficult to determine if the two stimuli are presented through different sets of electrodes.) The dividing partition contained a wedge-shaped notch lined with silicone lubricant, into which the fish was fitted. The stimuli were provided through two sets of electrodes. The head compartment received an electronic addition of S1 and S2 between a silver mouth electrode (Ei), inserted through the respirator tube, and two silver wires lateral to the body wall (Ee). Since, for relatively small S2 intensities, the depth of the phase modulation is equal to the amplitude ratio, $|\mathrm{S} 2| \mid$ $|\mathrm{S} 1|$, small phase modulations could be inferred from this ratio, even if they could no longer be read from the oscilloscope (see Fig. 2, $B$ and $C$ ). The tail received an $\mathrm{Sl}$ alone, administered between an insect pin (Ei) inserted into the dorsal musculature and a pair of lateral electrodes (Ee). The amplitude of the $\mathrm{S} 1$ at the tail was set $10 \mathrm{~dB}$ larger than that in the head compartment so that, should the tail compartment be contaminated by leakage of the $\mathrm{S} 2$, the amplitude ratio of $|\mathrm{S} 2| /|\mathrm{S}| \mid$ would be still smaller than in the head compartment. Electrical isolation between the two compartments was $-60 \mathrm{~dB}$ for the frequencies used. With this stimulus regime, the fish was able to determine the sign of the frequency difference by comparing phase values between the two chambers.

The two stimuli, S1 and S2, were produced by waveform generators (Exact $129 \mathrm{~GB})$. The S2 frequency was computer-controlled to alternate every $25 \mathrm{sec}$ between frequencies $4 \mathrm{~Hz}$ lower and $4 \mathrm{~Hz}$ higher than the $\mathrm{S} 1$. Four Hertz has been determined to be in the optimal range of frequency differences for eliciting JARs (Bullock et al., 1972; Partridge et al., 1981). The S1 frequency was set close to the fish's electric organ discharge frequency so as to stimulate its clectroreceptors optimally (Hopkins, 1976; Zakon and Meyer, 1983).

\section{Physiology}

Our experimental procedures were similar to those used in earlier intracellular studies (Heiligenberg and Dye, 1982; Heiligenberg and Rose, 1985). After topical application of a local anesthetic (Xylocaine), a small hole was drilled through the translucent bone covering the area to be studied. A silver ground wire was placed at the edge of the hole. Electrodes ranged in resistance from $30-500 \mathrm{M} \Omega$ and were filled with either $3 \mathrm{M} \mathrm{KCl}$ or $2-10 \% \mathrm{HRP}$ (Sigma VI) solution in $0.5 \mathrm{M} \mathrm{KCl}$ and 0.1 Tris buffer (pH 7.4) or 10\% Lucifer Yellow (Sigma) in $0.1 \mathrm{M} \mathrm{LiCl}$.

Three different stimulus regimens were utilized, two of which served to determine the phase-coding system's ability to code small temporal disparities. The first set of experiments determined the amount of jitter in the timing of spikes in the phase-coding system as a function of stimulus intensity. The second, related, set demonstrated to what degree torus phase coders could follow small modulations in the timing of zerocrossings. The third set of experiments included those associated with dye injection, receptive field identification, latency measurements, and analysis of the relative amplitudes of orthodromic spike components.

To measure jitter as a function of stimulus intensity, the fish were stimulated by an $S 1$ applied between an electrode in the mouth and another around the tail. Spikes were recorded either from phase-coding primary afferents in the recurrent branch of the anterior lateral line nerve, or from phase-coders (afferents from the electrosensory lateral line lobe or from giant cells in lamina VI) in the midbrain torus. The
A

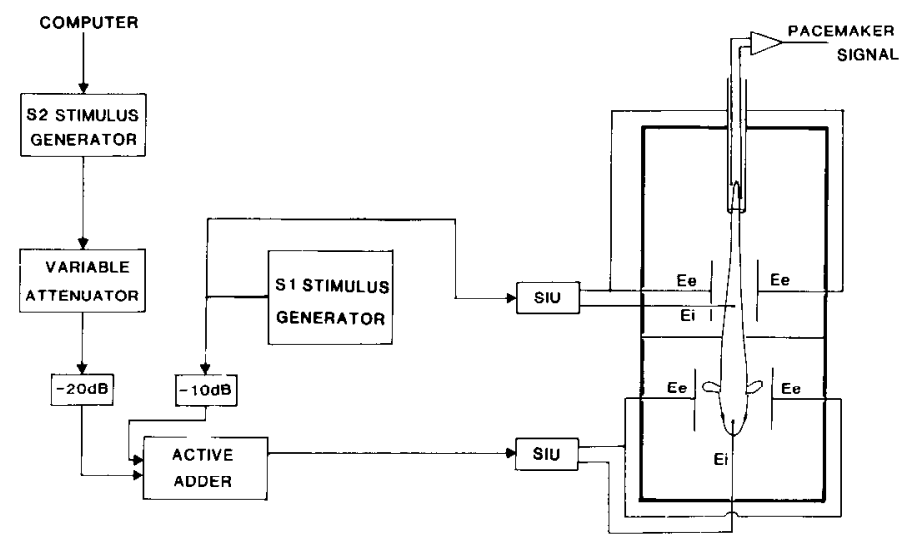

B

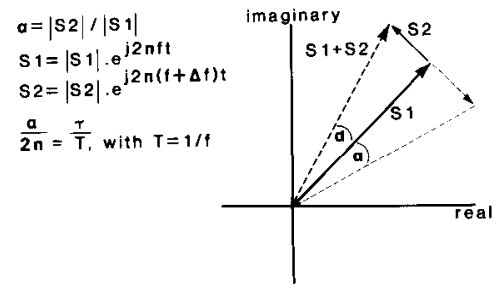

C

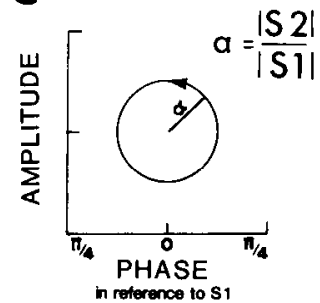

Figure 2. A, Flow chart of the clcctronic stimulus modulation that produces a Jamming Avoidance Response in a curarized fish. The amplitude of the S2 (neighbor mimic) is set initially to $10 \%$ of the S1 amplitude; then the two signals are added. The combined signal is modulated in amplitude and phase, as shown in $C$. We could not measure directly the very low $S 2$ stimulus amplitudes needed to produce a threshold response. Consequently, we used a variable attenuator to reduce the $\mathbf{S} 2$ signals by measurable amplitudes. However, the variable attenuator did not function reliably at very low amplitudes. In order to keep the attenuator in the reliable range, we used a second attenuator to further reduce the amplitude by $20 \mathrm{~dB}$. The fish is shown in the experimental chamber on the right, with stimulation electrodes inside $(E i)$ and outside $(E e)$ the body. Although the electric organ discharge is silent, the pacemaker command to the electromotor neuron can be measurcd by the suction clectrode placed over the tail tip. $B$, Computation of maximal temporal disparity, $\tau$, between zero-crossing of the stimuli, S1, and S1 and S2. The two stimuli, S1 and S2, are represented as complex vectors. $\mathrm{S} 1$ rotates around the origin with the angular velocity $2 \pi F$, while $\mathrm{S} 2$, attached to the tip of $\mathrm{S} 1$, rotates at an angular velocity, $2 \pi(F+\Delta F)$. The maximal phase angle, $\alpha$, between Sl and $\mathrm{S} 1+\mathrm{S} 2$ is obtained at the moment that $\mathbf{S} 2$ forms a right angle with $\mathrm{S} 1$. This maximal angle, $\alpha$, corresponds to a temporal disparity, $\tau$, between zero-crossing of the real components of S1 and S2. The peak-to-peak temporal disparity between $\mathrm{S} 1$ and $\mathrm{S} 1+\mathrm{S} 2$ equals $2 \tau$. Note that the animal only perceives the real components of the vectors displayed in the diagram. $C$, The Lissajous-like figure illustrates how the maximal modulation in amplitude and phase can be computed from the amplitude ratio, $\alpha$, between $\mathrm{S} 2$ and $\mathrm{S} 1$. This maximal phase angle, $\alpha$, between the combincd signal, S1 I S2, perceived in the head region, and the pure S1 signal, perceived in the tail region, equals $|\mathrm{S} 2| /|\mathrm{S} 1| \mathrm{rad}$ (for computation, see Fig. $2 B$ ). The time for full rotation $(2 \pi)$ of $\mathrm{S} 1$ is 2500 $\mu \sec (400 \mathrm{~Hz})$, and the maximum time difference corresponding to the value of $\alpha$ is $2500 \times \pi / 2 \mu \mathrm{sec}$ for small values of S2. The peak-to-peak modulation is twice as large.

timing of 1024 intracellular spikes was measured with respect to the sync pulse of the function generator, delivering the SI waveform, and their SD used as a measure of jitter. Each spike triggered a Schmidt trigger at the positive steepest slope of the spike, the point with the lowest jitter. Noise levels were less than $1 \mathrm{mV}$, and spikes were between 40 and $50 \mathrm{mV}$ in amplitude, with capacity compensation on the intra- 

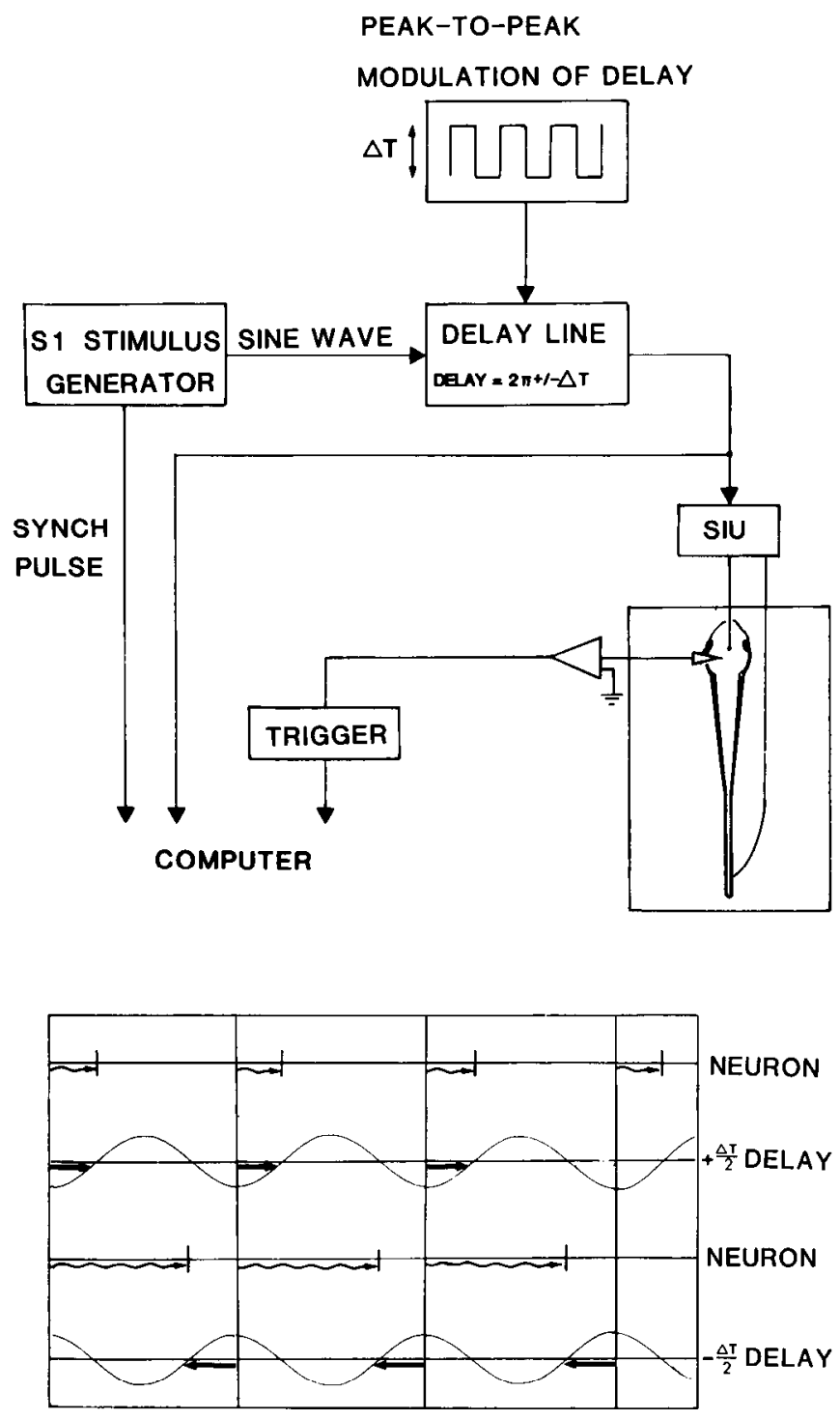

Figure 3. Flow chart of the experiment to measure the accuracy of the phase-coding system. A sine-wave electric organ discharge substitute, $S 1$, is alternately delayed or advanced by a time $\Delta T / 2$ every 114 stimulus cycles. The magnitude of the delay was varied from 22 to $0.5 \mu \mathrm{sec}$, and the ability of each neuron to reflect timing of the S1 accurately was measured over 1024 stimulus cycles. Below are response characteristics of an ideal neuron. Each spike is measured with respect to a sync pulse from the $S 1$ generator. Response time for each spike is indicated by the wavy arrow, while delay is shown by the thick arrows.

cellular amplifier (WPI M701) at its lowest setting. This reduced the spike height by roughly $60 \%$, but also served to filter out high-frequency noise, which adds jitter to the system. Each measurement was repeated from 3 to $10 \times$; the stimulus intensity was then raised by $10 \mathrm{~dB}$ (approximately a factor of 3 ) and the experiment repeated. The jitter intrinsic to the recording system was measured by placing the recording electrode in the water next to the head. We recorded a square-wave signal of $1 \mathrm{~V} / \mathrm{cm}(1000 \times$ greater than the electric organ discharge), so we could neglect the jitter inherent in the stimulus. The jitter remaining must therefore have been due to the electronic equipment. I atencies of events related to the $S 1$ sync pulse were measured with a $10 \mathrm{MHz}$ computer-controlled clock.

The second experiment tested the phase-coding system's ability to discriminate between small temporal modulations. The procedure is diagrammed in Figure 3. The response of torus phase coders was recorded while the S1 stimulus was alternately phase-delayed or phaseadvanced over periods of 114 stimulus cycles. The timing of the spike response was measured in reference to the unmodulated sync pulse of the $\mathrm{Sl}$ with $0.1 \mu \mathrm{sec}$ resolution. The peak-to-peak modulation in the phase of the $S 1$ stimulus was measured by placing the recording electrode in the water next to the head. This modulation varied from a maximum of $25 \mu \mathrm{sec}$ to a minimum of $0.5 \mu \mathrm{sec}$.

All other experiments on the phase-coding system were confined to the midbrain torus. Most were carried out in a chamber similar to that described by Heiligenberg and Bastian (1980). This chamber divides the fish into five isolated compartments, so that the signals mimicking the electric organ discharge (S1), and those mimicking the conspecific (S2) could be administered to any or all compartments. This allowed receptive fields to be localized to individual compartments. Once the receptive fields were identified, latencies of nerve and torus units were measured $(n=200)$ (Heiligenberg and Dye, 1982).

\section{Morphology}

Dye injection was performed as in Heiligenberg and Dye (1982) and IIeiligenberg and Rose (1985). The fish were perfused with $4 \%$ paraformaldehyde after Lucifer injections, and with $2 \%$ glutaraldehyde or $2 \%$ paraformaldehyde after HRP injections. Sixty micron sections were cut on a vibratome and the HRP sections reacted, using a modified Hanker-Yates protocol (Heiligenberg and Dye, 1982).

\section{Results}

We show that the Jamming Avoidance Response may be elicited by phase modulations of the stimulus that are smaller than 1 $\mu$ sec. This extraordinary temporal resolution has its origins in the responses of the neurons of the phase-coding system, whose acuity of temporal resolution appears to be inferior to that of the behavior. Nevertheless, intracellular recordings from the cells of this system reveal increasing accuracy from the level of primary afferents to the midbrain.

\section{Behavioral sensitivity of the phase-coding system}

A typical JAR is shown in Figure 4 (top inset). This behavior was triggered by a jamming stimulus, $S 2$, that alternated between frequencies $4 \mathrm{~Hz}$ higher and lower than the signal substituted for the fish's electric organ discharge (S1).

The JARs of three fish were tested using the two-chamber arrangement described (see Fig. 2). The amplitude ratio of S2 to $S 1$ is identical to the relative amplitude modulation of the combined signal; i.e., for $|S 1| /|S 2|=0.1$, the depth of the amplitude modulation is $10 \%$. With small relative intensities of $\mathrm{S} 2$, the ratio of $|\mathrm{S} 2| /|\mathrm{S} 1|$ also approaches the maximum phase modulation, measured in radians, of the signal experienced in the head region compared with the unmodulated signal in the tail region (see Fig. $2 B$ ). This modulation in phase is equivalent to a temporal disparity between signals in the head and tail regions ranging from tens of microseconds to tenths of microseconds, depending on the relative amplitude of S2. By switching the frequency difference between $S 1$ and $S 2$ back and forth between +4 and $-4 \mathrm{~Hz}$, regular shifts of the animal's electric organ discharge frequency may be elicited, and such JARs may be reliably measured, even as they approach threshold performance (for methods, see Heiligenberg et al., 1978; Heiligenberg and Bastian, 1980).

Three Eigenmannia with electric organ discharge rates of approximately 300,400 , and $500 \mathrm{~Hz}$ were tested. A stimulus rcgime employing an $|\mathrm{S} 2| /|\mathrm{S} 1|$ ratio of 0.1 , measured in the head compartment, elicited strong JARs. In this case, the peak-topeak modulations in temporal disparity were 106 (open triangle, Fig. 4 and inset), 79, and $63 \mu \mathrm{sec}$, respectively. The $|\mathrm{S} 2| /|\mathrm{S} 1|$ ratios were decreased in a stepwise fashion from $0.01,0.003$, $0.001,0.0003$, to 0.0001 , where detectable JARs were no longer visible after averaging 10 consecutive trials. A JAR is still clearly present at an $|\mathrm{S} 2| /|\mathrm{S} 1|$ ratio of 0.001 (filled triangles, Fig. 4 and inset), which corresponds to a peak-to-peak time difference of $1.0 \mu \mathrm{sec}$ in the $300 \mathrm{~Hz}$ fish. The $400 \mathrm{~Hz}$ fish continued to perform detectable JARs at ratios of 0.0003 (238 nsec). A similar acuity in temporal resolution was observed in the other two fish 


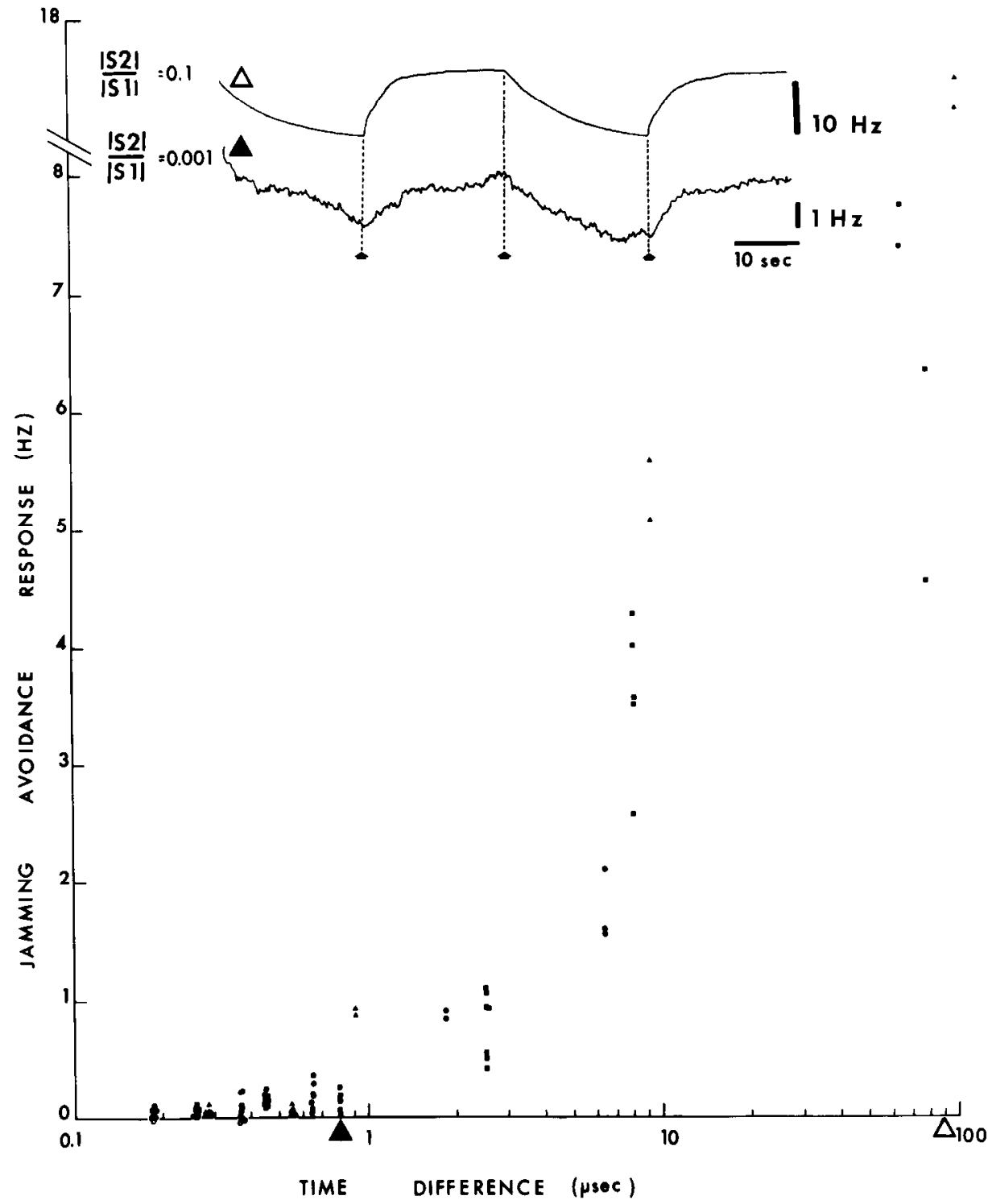

Figure 4. Jamming Avoidance Response measurements as a function of the ratio between the interfering sinewave stimulus (S2) and the sine-wave stimulus (S1), which substitutes for the animal's clectric organ discharge. Each symbol represents JAR values of an individual fish: $\boldsymbol{\Delta}$, a fish with an electric organ discharge rate of 333 $\mathrm{Hz}$; , one with a rate of $400 \mathrm{~Hz}$; and -, one with a rate of $500 \mathrm{~Hz}$. Values on the ordinate are mean frequency shifts of the animal's pacemaker in response to a $100 \mathrm{sec}$ stimulation in which the sign of the $4 \mathrm{~Hz}$ frequency difference between $\mathbf{S} 1$ and $\mathrm{S} 2$ was altered every $25 \mathrm{sec}$ (inset, arrows). A positive response implies that the animal lowers its frequency in response to a higher-frequency signal than its own, and raises its frequency in response to a lower-frequency signal. Small values, symmetrically distributed around zero, imply that the fish cannot detect the change in sign of the frequency difference. The fish shows small but consistently positive responses to signals with temporal modulations as small as $0.4 \mu \mathrm{sec}$ peakto-peak. There is a finite time before the fish "decides" whether to raise or lower its electric organ discharge frequency. For $\mathrm{S} 2$ signals of high intensity, this period is $100 \mathrm{msec}$ for a decrease (Bullock et al., 1972), and 300 msec for an increase in frequency. At threshold, a $300 \mathrm{~Hz}$ fish takes 200 msec before decreasing its frequency, and $300 \mathrm{msec}$ before increasing its frequency. JAR traces for large and small temporal disparities are shown in the inset. The upper trace is a single record of frequency changes associated with an above-threshold JAR. The lower trace shows an average of 10 consecutive trials to an $|\mathrm{S} 2| /|\mathrm{S} 1|$ ratio of 0.001 (temporal disparity, 0.8 $\mu \mathrm{sec})$. Note the difference in scale between the two cases.

(Fig. 4). Thus, untrained fish were able to detect modulations in the timing between the head region signal and the tail region signal of less than $0.4 \mu \mathrm{m}$ peak-to-peak.

These data also demonstrate that the animal detects relative amplitude modulations as small as 0.0003 , or $0.03 \%$.

\section{Convergence and timing of spikes in the phase-coding system}

The phase-coding system is an electrotonically connected chain of neurons that converges on the giant cells of the torus (Fig. 5 ). This system provides a fast and accurate code of the relative timing of the electric organ discharge signal in various parts of the body surface. Phase-coding receptors are innervated by primary afferents, which form gap junctions on the phase-coding spherical cells of the electrosensory latcral line lobe. These cells, in turn, form gap-junction contacts on the giant cells of lamina VI in the midbrain torus (Fig. 5).

The previous section detailed the extreme sensitivity of the fish to time disparities. How does the ability to discriminate timing differences as small as $400 \mathrm{nsec}$ emerge? This problcm was addressed by a combination of physiological and anatomical approaches, which were carried out in four stages. The first was a measure of the convergence in the phase-coding system. The second set of experiments determined the amount of jitter in the timing of the spikes in the phase-coding system, while the third series demonstrated how well the phase coders follow small modulations in the timing of a signal. The fourth experimental series provided an electrophysiological and morphological description of the properties of phase-coding afferents from the electrosensory lateral line lobe and torus giant cells.

\section{Convergence in the phase-coding system}

A number of morphological adaptations underlie the increasing acuity of temporal resolution displayed by the elements of the phase-coding system. The system is characterized by fast conduction times mediated by thick axons and gap-junction synapses between its cells. Primary afferent phase-coders from one side of the body terminate in the ipsilateral electrosensory lateral line lobe, where they form electrotonic synapses upon the cell bodies of the spherical cells (Maler et al., 1981). The electrosensory lateral line lobe is divided into four segments: medial, centromedial, ccntrolateral, and lateral. Each segment contains a map of the ipsilateral body surface, and the latter three receive identical input, as each phase-coding primary afferent process 


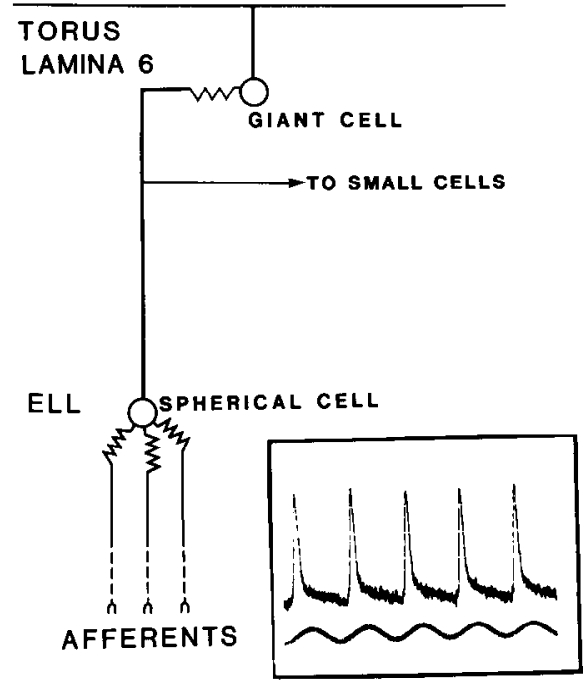

Figure 5. Connections of the phase-coding system. Phase-coding receptors on the body surface are innervated by phase-coding primary afferents whose cell bodics are located in the ganglion of the anterior lateral line nerve. These afferents form gap-junction synapses on the spherical cells of the electrosensory lateral line lobe $(E L L)$, and these cells project to the contralateral lamina VI of the torus. Spherical cell afferents form gap-junction synapses on the cell bodies of giant cells and mixed synapses upon the dendrites of small cells (Carr et al., in press). Resistor symbols indicate gap-junction synapses. Insert, a typical in tracellular recording from a torus phase coder. Stimulus cycle, $2 \mathrm{msec}$; resting potential, $-80 \mathrm{mV}$; spike height, $100 \mathrm{mV}$.

divides into three to form a terminal field in each of the tuberous segments (Heiligenberg and Dye, 1982).

A count of the number of spherical cells per map has yielded a major difference in cytology between the three tuberous maps. In one individual, the centromedial map had 505 spherical cells; its neighbor, the centrolateral map, had 170; and the most lateral map, 88 spherical cells. The spherical cells are confined to a single lamina of the electrosensory lateral line lobe, and are unequally distributed, being densest at the rostral or head portions of each map. This reflects the high density of electroreceptors on the head. Giant cells are also densest in the rostral portions of lamina VI.

A count of the giant cells in lamina VI yielded 380 cells, with no corrections for split nucleoli. Thus, with approximately 1500 spherical cells in both ELLs, and 380 giant cells, the convergence of spherical cells onto giant cells is about $4: 1$.

\section{Jitter in spike timing}

Jitter in the timing of spikes was measured for 43 primary afferent phase-coders and, within lamina VI of the torus, 40 phase-coding afferent terminals from the electrosensory lateral line lobe or from torus giant cells (these last two cannot be distinguished without intracellular labeling). The timing of each phase-coder spike was measured with respect to the sync pulse of the stimulus generator, which provided an electric organ discharge mimic, $\mathrm{S} 1$, of constant frequency. Action potentials at least $60 \mathrm{mV}$ height were recorded intracellularly (see records in Figs. 5 and $10 B$ ).

Figure 6 and inset show that, although some primary afferent phase-coders were as good as torus units in their ability to lock their spikes to a particular phase of the stimulus, the vast majority display more variability in timing of firing than do the neurons in the medulla and midbrain that they converge upon. Almost all torus units fire with very small standard deviations (SDs) $($ mean $=11.4 \mu \mathrm{sec}$, standard error $(\mathrm{SE})=3.4 \mu \mathrm{sec}, n=$
40), while the SDs of the primary afferent spikes were almost $3 \times$ larger (mean $=30 \mu \mathrm{sec}, \mathrm{SE}=25.4 \mu \mathrm{sec}, n=43$ ). These measures include the jitter introduced by the recording equipment. This jitter was measured by recording with the same electrode the timing of a square-wave stimulus, $1000 \times$ greater than the $\mathrm{S} 1$, in the vicinity of the fish; an SD of $0.7 \mu \mathrm{sec}$ was obtained.

The phase-coding system is relatively immune to differences in stimulus intensity, as it fires 1:1 over a broad range of stimulus intensities, unlike the amplitude-coding system (Scheich et al., 1973; Szabo, 1967). The 1:1 firing breaks down only at very low stimulus intensities. The precise time of the spike, however, is more jittery in the primary afferents than in the torus. Do they improve equally with increased stimulus intensity? After the jitter of each neuron was measured at normal stimulus intensity, it was tested again with measurements at an intensity $3 \times$ higher (Fig. 6).

With increasing stimulus intensity, the jitter in the timing of firing decreases more for primary afferents than for higher-order phase-coders. The points on the $1: 1$ line (Fig. 6) would indicate complete immunity to intensity changes. The accuracy of timing of most torus units is improved by increasing stimulus intensities. The improvement, however, is not as dramatic as the threefold improvement shown by many phase-coding primary afferents (3:1 line). At normal stimulus intensities, the primary afferent population was significantly more jittery than the torus population (Mann-Whitney $U$ test; $p<0.00003$ ) (histograms in Fig. 6).

It is also possible that these measures do not indicate the system's best performance, as impaling a neuron may decrease its ability to fire at a precise time with respect to the stimulus. In those cases in which we were able to maintain a clean and stable intracellular penetration for many minutes, measures of jitter remained constant. Intracellular recordings were used consistently because of the overwhelming field potential in lamina VI. All previous extracellular recordings in the literature represent measures of field potentials, or of single units contaminated by field potentials. Uncontaminated recordings may only be obtained by very-high-resistance electrodes.

\section{Time resolution}

The ability of 90 units to code the timing of an S1 signal, alternately delayed and advanced in phase for periods of 114 stimulus cycles over a total of 1024 stimulus cycles, was determined (see Methods and Fig. 3 for details). The peak-to-peak time difference between advanced and delayed signals could be varied from 25 to $0.5 \mu \mathrm{sec}$. The response latencies of each neuron, as a function of the current stimulus cycle, were averaged for 10 experiments (data taken from a single toral unit is displayed in Fig. 7, center column). The means of the latencies obtained for the delayed and advanced stimulus cycles were compiled into pairs of histograms that reflect a normal distribution of firing about a mean (Fig. 7, left column). The means of histograms were separated by a value corresponding to the peak-to-peak phase difference in the stimulus regime.

Data were gathered for three temporal disparities: 22,9 , and $0.5 \mu \mathrm{sec}$. These were comparable to peak-to-peak phase modulations obtained for a $400 \mathrm{~Hz}$ signal at $|\mathrm{S} 2| /|\mathrm{S} 1|$ ratios of $0.027,0.011$, and 0.0006 , respectively. The distributions of latencies for delayed and advanced stimulus cycles were clearly different for the 22 and $9 \mu \mathrm{sec}$ peak-to-peak phase modulations (Fig. 7; data for $9 \mu \mathrm{sec}$ not shown). For a modulation of 0.5 $\mu \mathrm{sec}$, however, the differences were barely discernible. Figure $7 B$ compares the time-locking of the neural responses (above) with recordings of the stimulus in water for a modulation of 0.5 $\mu$ sec. Recordings of the stimulus alone serve to take into account the jitter inherent in the recording system, allowing us to assess the relative change in the jitter of the neuron. With the SD of the recording of the neuron as $3.9 \mu \mathrm{sec}$, and the SD of the 


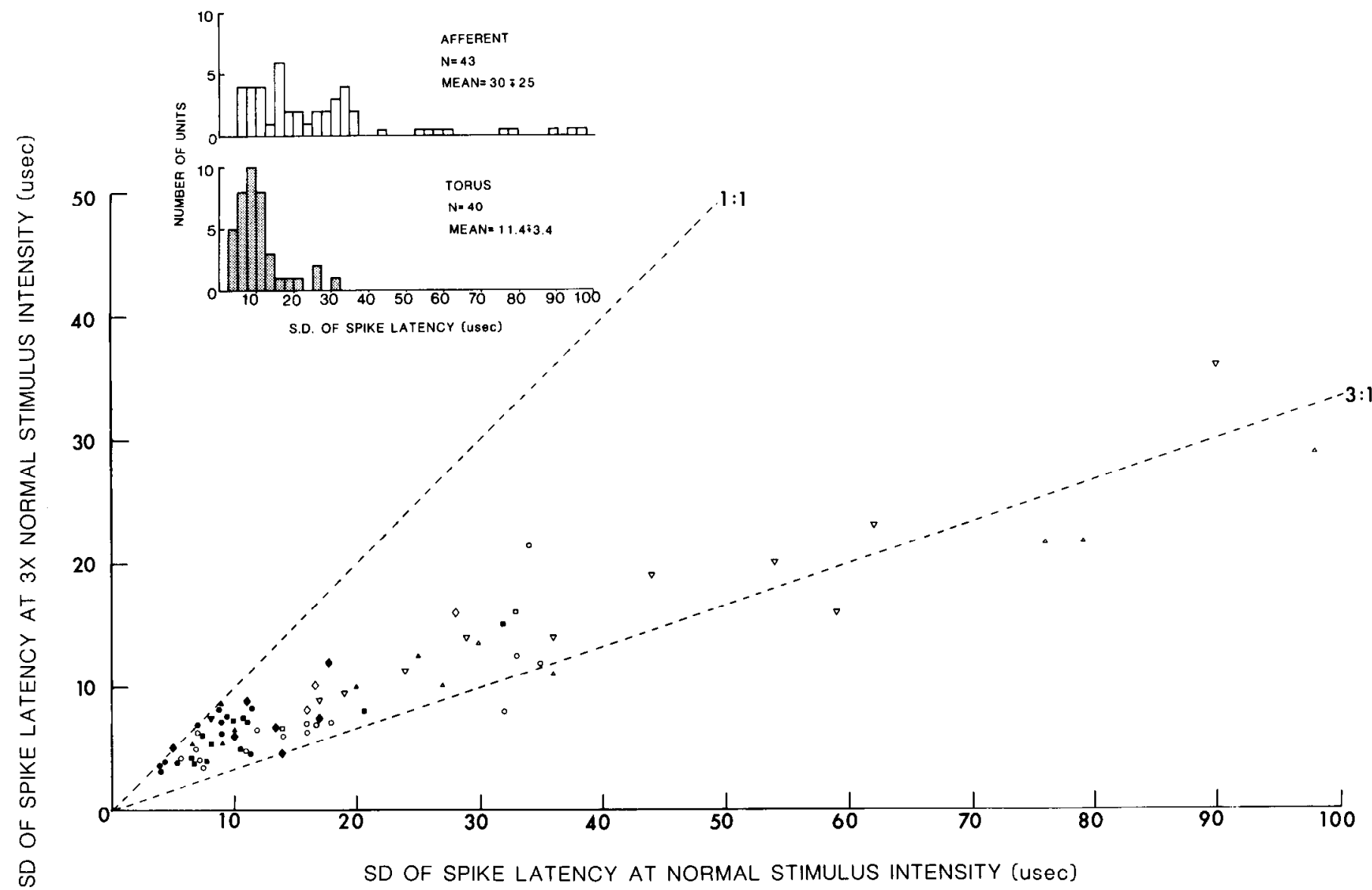

Figure 6. Jitter in the phase-coding system. The SD of the latency of firing of units in the anterior lateral line nerve and in the torus was measured as a function of stimulus intensity over 1024 stimulus cycles. The SD was taken as a measure of the neuron's jitter, determined at normal ( $1 \mathrm{mV} /$ $\mathrm{cm}, a b s c i s s a$ ) and $3 \times$ normal (ordinate) stimulus intensities. The smallest SD was $4 \mu \mathrm{sec}$ for a torus unit. The jitter of torus phase-coders (closed symbols) was far less than that of phase-coding afferents (open symbols) recorded in the nerve. The five symbols represent data from different fish. Inset, SD of nerve and torus populations at normal stimulus intensities. The two populations are significantly different at $p<0.00003$ at both normal and $3 \times$ normal stimulus intensities.

recording equipment alone as $0.7 \mu \mathrm{sec}$, the jitter inherent to the response of the neuron alone would be $\sqrt{15.2-0.5}=\sqrt{14.7}=$ $3.8 \mu \mathrm{sec}$ (this assumes addition of neuronal and electronic noise). For a sampling period of $200-300 \mathrm{msec}$, the latency of the behavior, this accuracy in the timing of individual spikes does not suffice to resolve phase modulations of $0.5 \mu \mathrm{sec}$ peak-topeak. The animal must, therefore, average either successive responses of individual neurons over time, or nearly synchronous responses of many neurons. The two peaks in Figure $7 B$ are discernibly different, but they represent averages of approximately 5000 spikes in each histogram.

\section{Physiology}

The phase-coding system is characterized by fast conduction times, mediated by large-diameter axons and gap-junction connections between neurons. Phase-coding afferents from the spherical cells of the electrosensory lateral line lobe ascend in the lateral lemniscus to the contralateral torus, where they terminate on a giant cell of lamina VI (Figs. 5 and $8 \mathrm{C}$ ). Each giant cell reccives afferent input from at least four spherical cell afferents (see above; Carr et al., in press), and intracellular recordings from phase-coding afferents close to their terminals on the giant cells display numerous small spikelets when no stimulus is present (Fig. 8B). This suggests that the electrotonic synapse betwecn afferent and giant cell is nonrectifying, as these spikelets are presumably antidromic invasions from the giant cell. When the stimulus intensity is raised to normal levels, the jitter in the firing of the phase-coding afferents decreases and the spikelets converge into a single action potential, as would be expected on the basis of synchronous input (see Fig. 10).

A horizontal view of lamina VI of the torus shows an HRPfilled giant cell, as well as the somatotopic order of the pisciculus created by afferent input from electrosensory lateral line lobe phase-coders (Fig. 9). Recordings from the giant cells are region-specific. Soma spikes are smaller in amplitude and longer in duration than those from the initial segment, and often have postsynaptic potentials (psps) on their rising phase (Fig. 10 A, bottom). If the giant cell is underdriven, the afferent inputs do not arrive with sufficient synchrony to cause a spike in the giant cell (Fig. 10B, center), and large psps are recorded. This provides a direct demonstration of the averaging of afferent input: As the stimulus intensity is increased, the psps "congeal" into a single spike in the soma (Fig. 10B). This spike is propagated throughout the giant cell, while the psps produced at low stimulus intensities undergo a decrement with distance from the soma. At a distance of $2000 \mu \mathrm{m}$ from the soma, they are no longer apparent (Fig. 10C).

\section{Discussion}

\section{Detection of temporal disparities}

We have used the Jamming Avoidance Response as a behavioral assay to determine the limits of Eigenmannia's ability to dis- 


\section{ACCURACY OF PHASE CODING}

\section{POST STMULUS TME HSTOGRAM}

A
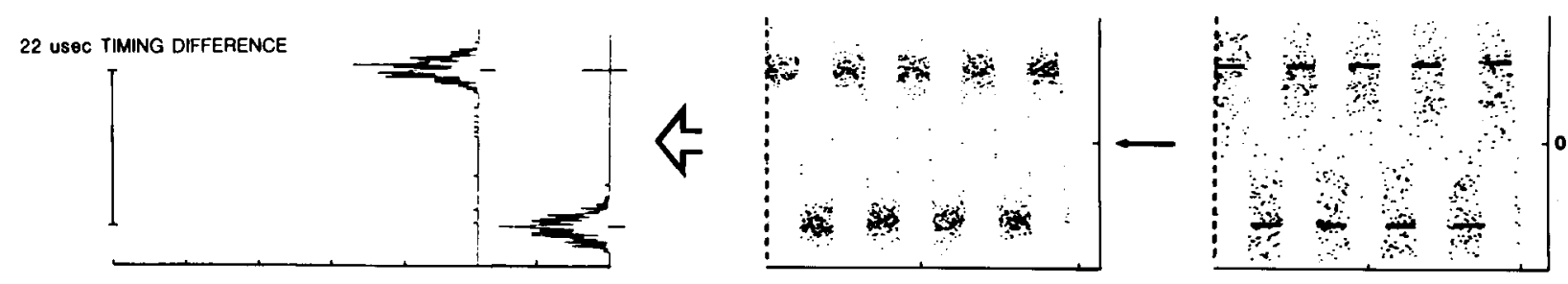

B

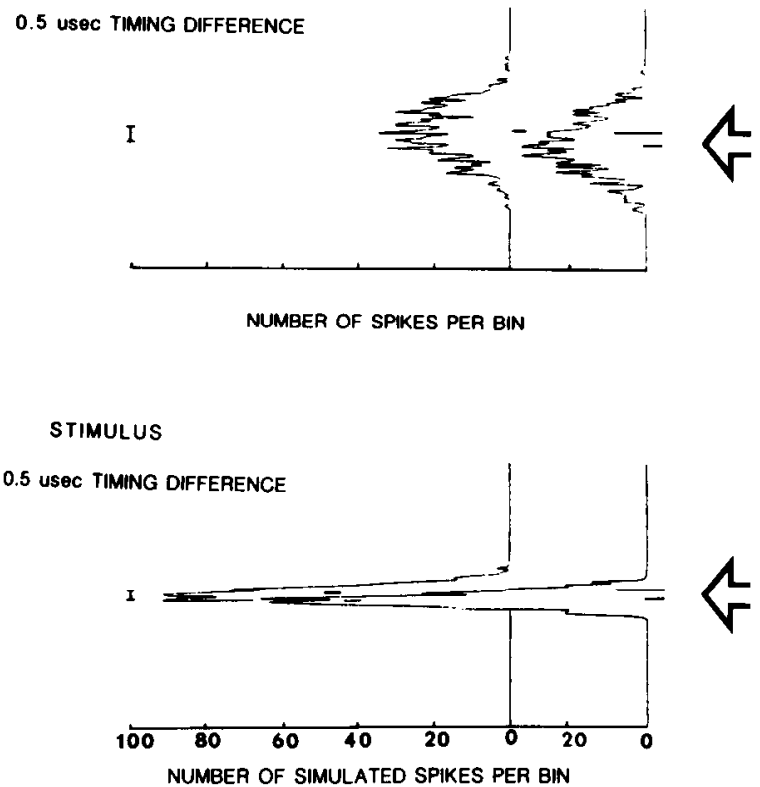

\section{RAW DATA SAMPLE}

MEAN OF TEN SAMPLES
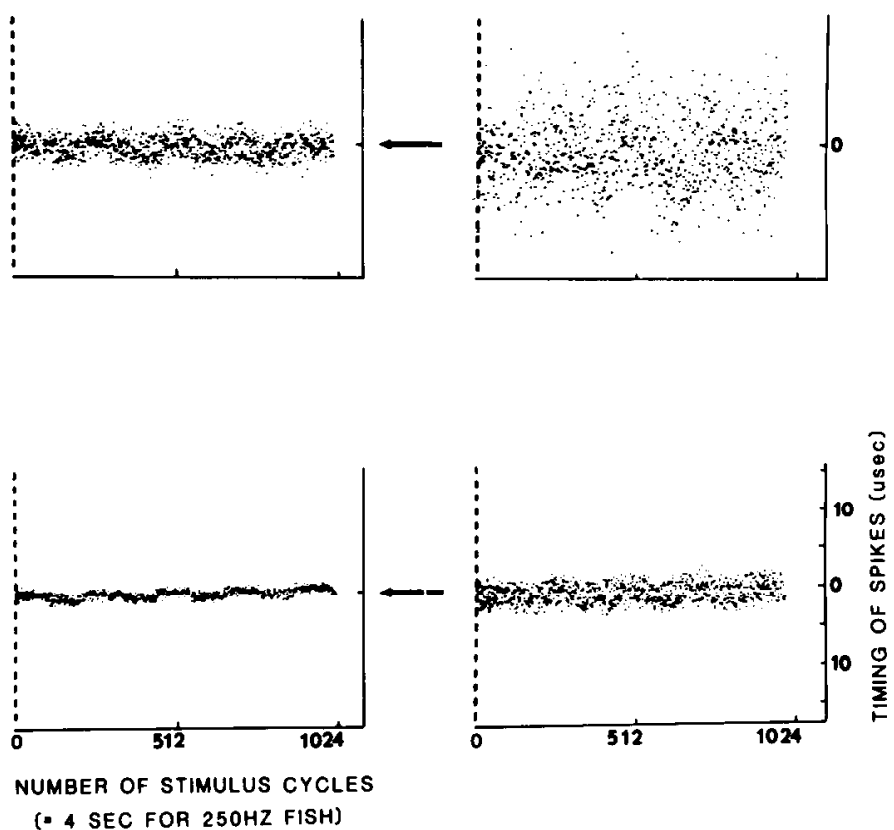

(. 4 SEC FOR $250 \mathrm{HZ}$ FISH)

Figure 7. Accuracy of the phase-coding system. We measured the ability of a torus phase-coder to follow an S1 signal alternately delayed and advanced in time with reference to the unmodulated sync pulse of the stimulus generator. The peak-to-peak timing difference between advanced and delayed S1 varied from $22(A)$ to $0.5(B) \mu \mathrm{sec}$. The $0.5 \mu \mathrm{sec}$ difference represents the limit of the fish's behavioral ability to discriminate phase modulations. Far right column, Diagrams show the timing (ordinate) of 1024 successive spikes, triggered by a stimulus either advanced or delayed with respect to a reference ( 0 on ordinate) over periods of 114 successive spikes. Dark bars in the top diagram indicate the timing of the stimulus. These bars were omitted in the lower diagrams. Bottom diagram, timing of the stimulus measured with the same electronic circuitry. The scale of timing of spikes is the same for all diagrams in the right and center columns. Center column diagrams, Average timing values obtained from 10 repetitions of the experiment; distribution of these values is plotted in histograms on the left. These histograms were compiled separately for spikes triggered during the advance and delay phases of the stimulus; spikes recorded during the transitions were discarded. Each histogram thus reflects the distribution of approximately 500 mean firing latencies, each based upon a sample of 10; the SD of individual latencies is therefore $\sqrt{10}$ larger than the SDs reflected in the histogram. The histograms of the neuronal responses for $0.5 \mu$ sec timing differences are different at the 0.001 level ( $t$-test). The time scales of the figures in the left-hand column were chosen individually and are indicated by separate marks showing the timing differences in the stimulus regime. The means of the histograms are indicated by horizontal lines and marked by pairs of arrows.

criminate small temporal disparities. We found that this fish is able to detect temporal disparities as small as 400 nsec.

Torus neurons, which respond to temporal disparities, readily discriminate modulations in the timing of a signal on the order of tens of microseconds (Bastian and Heiligenberg, 1980a, b). Sensitivity to the difference in the timing of electric signals received by different regions of the fish's body surface arises in the small cells of lamina VI (Heiligenberg and Rose, 1985). These neurons are unresponsive to amplitude modulations but respond strongly for a particular range of time disparities; a change in firing rate of $25 \%$ can occur in response to a $10 \mu \mathrm{sec}$ change in timing between signals from two specific parts of the body surface.

This feat of sensitivity may be unequalled among vertebrates, although it finds a close parallel in binaural comparisons of the auditory systems of birds and mammals. Psychophysical studies have shown that subjects are able to localize the azimuth of a frontal noise target with an accuracy of about $1^{\circ}$ (Mills, 1958, 


\section{AFFERENT}

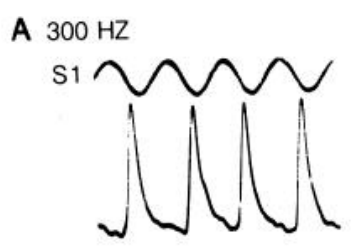

B

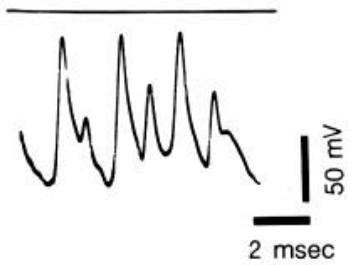

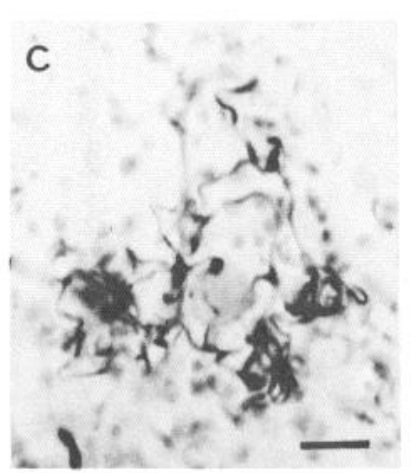

Figure 8. Phase-coding afferents from the electrosensory lateral line lobe. The spherical cell axons terminate upon the giant cell somas. A, A typical axon spike triggered by an S1 stimulus cycle may be recorded close to the terminal. $B$, When no stimulus is present, postjunctional potentials (pjps) may also be recorded in these terminals. This suggests that the gap-junction synapse upon the giant cell is nonrectifying, and that these pjps represent antidromic giant cell spikes and psps from the target giant cell. They may vary in size up to $40 \mathrm{mV}$, and may represent psps from other afferents terminating upon the giant cell, as well as spikes from the giant cell itself. $C$, Photomicrograph of an HRP-filled phase-coding afferent terminal. The recording was made within $200 \mu \mathrm{m}$ of the giant cell soma, shown here surrounded by the terminals of a single axon. Average diameter: terminals, $1 \mu \mathrm{m}$; soma, about $20 \mu \mathrm{m}-\mathrm{a}$ ratio of 1:400 in surface area. Bar, $20 \mu \mathrm{m}$.

1972), or $6 \mu \mathrm{sec}$ in interaural time disparity (Tobias, 1972). Similar results have been obtained from trained barn owls (Knudsen et al., 1979). Neurophysiological studies in the owl have shown that some neurons are responsive to interaural timing differences in the region of tens of microseconds $(50 \%$ change in firing rate over $15 \mu \mathrm{sec}$ ) (Knudsen and Konishi, 1979; Moiseff and Konishi, 1981; Sullivan and Konishi, 1984; Takahashi et al., 1984). Similar results have been obtained in mammals. Simmons et al. (1983) suggest that bats are able to resolve interaural time differences as small as $500 \mathrm{nsec}$. In addition to comparing binaural inputs, bats also compare an echolocating cry and its echo. As a bat performs its final approach to a target, it receives the returning echo at shorter and shorter latencies, down to a few milliseconds (Suga, 1982). In the first demonstration of the detection of extremely small temporal disparities, Simmons (1979) reported that Eptesicus fuscus is able to detect fluctuations in this echo arrival time as small as $500 \mathrm{nsec}$. In a 2-choice experiment, bats discriminate targets on the basis of echo time modulations as small as $500 \mathrm{nsec}$. Another bat, $\mathrm{Mo}$ lossus, with a well-developed medial superior olive, has brain stem units that code binaural time differences in the same range ( $50 \%$ change in firing rate over $15 \mu \mathrm{sec}$ ) (Harnischfeger, 1980; Fig. 6 of Harnischfeger et al., 1985) as reported for the barn owl and Eigenmannia.

Temporal disparities in receptor stimulation are presumed to operate in a depth illusion in the visual system. In the Pulfrich pendulum illusion, a pendulum swung in a plane perpendicular to the line of sight is perceived as moving on an elliptical path in depth when one eye is covered by a neutral-density filter. The lower light intensity in one eye is presumed to delay local responses by some small amount and thus to bias the reported location of the traveling image. Psychophysical investigations

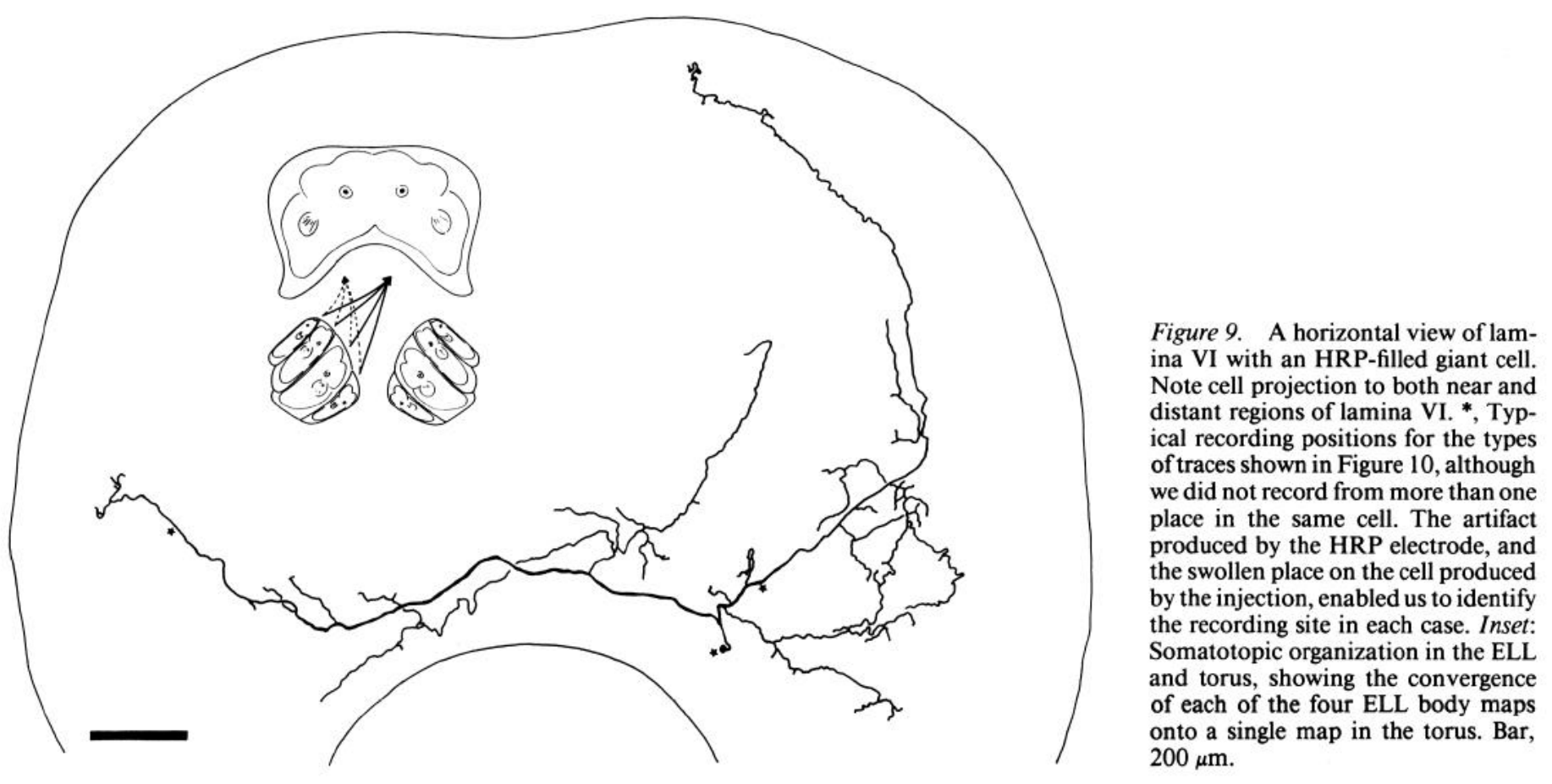


A SOMA

$600 \mathrm{HZ}$

B 300um

$500 \mathrm{HZ}$
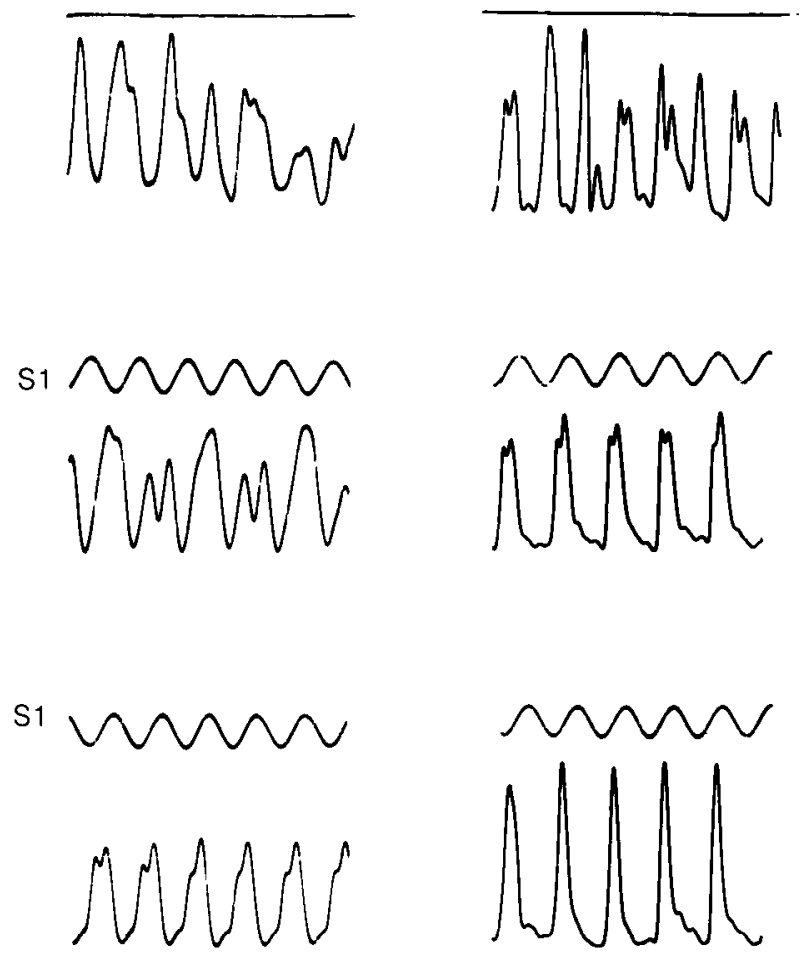

C 2000um

$400 \mathrm{HZ}$
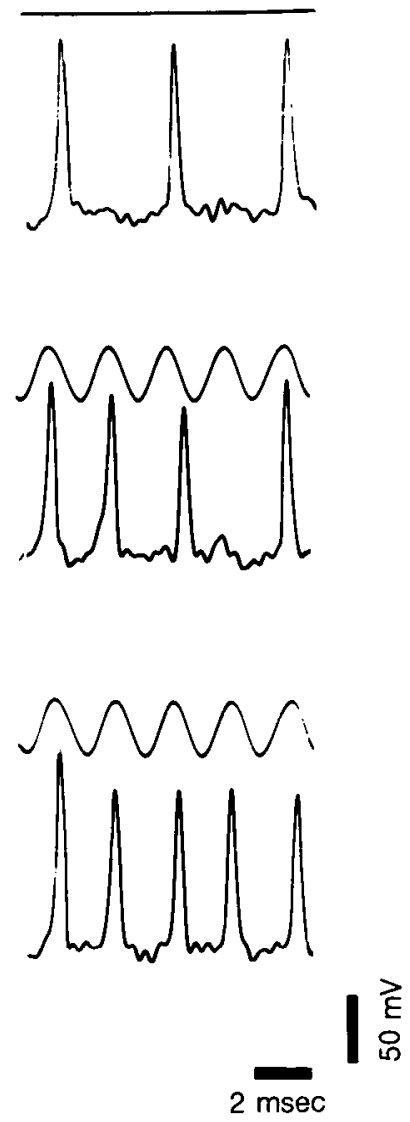

Figure 10. Waveforms of giant cell spikes recorded at proximal and distal sites on the neuron. Each recording site $(A, B$, and $C)$ represents a single experiment on a fish whose electric organ discharge rate is shown. The spikes are in response to an S1 stimulus that mimics the electric organ discharge and is shown above the spike trace. Top traces, the spontaneous activity at each recording site; middle traces, the units' responses to a stimulus insufficient to drive the unit $1: 1$; bottom traces, the units' normal responses, firing $1: 1$ with every $\mathrm{S} 1$ cycle. $A$, Potentials recorded in the giant cell soma. Those recorded in the soma were somewhat smaller in amplitude and longer in duration than those recorded close to the initial segment. Note that the electrotonic psps underlying the soma spike are revealed when the stimulus is removed; they may also be seen on the rising phase of the normal soma spike. When all stimuli are removed, the afferents that synapse on each giant cell fire spontaneously and asynchronously. Desynchronized psps may coincide to produce a spike in the giant cell. In the middle case, the cell is not ideally stimulated, and the psps do not arrive synchronously enough to produce a single potential in every case. A curious resonance appears, in which a single potential is produced alternately with psps. This may be due to $\mathrm{Na}+$ inactivation building up with the large potentials, and then diminishing when an action potential does not form (Bergman, 1968). $B$, Spikes and large psps recorded in a proximal giant cell axon within $300 \mu \mathrm{m}$ of the soma and initial segment. Loading of the spike-generating mechanism by the inactive terminals might account for the changes in spike duration seen during spontaneous activity. The psps seen with no stimulus are large $(20-40 \mathrm{mV})$ and relatively narrow. $C$, Spikes in the giant cell recorded in the contralateral torus, $2000 \mu \mathrm{m}$ from the soma. These are faster and more symmetrical than spikes recorded close to the initial segment. Note that not all spikes are of equal size; if the cell misses a response, or if there is no stimulus, the spikes may be as large as $120 \mathrm{mV}$. This may be due to adaptation in the form of increased $\mathrm{Na}+$ inactivation at high rates of activity.

suggest that the smallest perceived depths correspond to delays in the response of one eye on the order of $1 \mathrm{msec}$ (Enright, 1970; Lit, 1949).

\section{Emergence of behavioral sensitivity}

The sensitivity of Eigenmannia to temporal disparities arises, as in binaural processing, by virtue of CNS mechanisms. How well do responses of individual elements reflect the fish's behavioral performance? Intracellular recordings from circuit components have established the acuity of temporal resolution on the neuronal level, and found that the temporal resolution of primary afferents is inferior to the behavioral acuity.

The nervous system of Eigenmannia is beset by considerable discrepancies in receptor coding. We have observed considerable timing differences between signals that travel from the head and those that travel from the body, owing to the conduction delays inherent in the system. These conduction delays have been compensated for to some extent, as demonstrated by Heiligenberg and Dye (1982), who showed that primary afferents conducted with greater speed the more distant the receptor was from the brain. Compensation is improved upon in the torus, since, although head and tail regions of the same receptive field may have a mean of $0.75 \mathrm{msec}$ difference in latencies when stimulated separately, the giant cell followed the latency of the earliest input when the whole receptive field was stimulated. The behavioral correlate of these discrepancies in timing has 
been shown in experiments in which the fish is unable to perform a correct JAR if it is only able to compare the timing of zerocrossing from very distant parts of its body, such as the head and the tail (Heiligenberg and Bastian, 1980).

The system may best avoid the consequences of its imperfections (i.e., the conduction delays between head and tail) by the connections of the giant cells. Giant cells synapse only on the cell bodies of the phase-sensitive small cells, and they appear to make most of their synapses within $300 \mu \mathrm{m}$ of the soma (Carr et al., in press). Most of their other synapses are in the vicinity of their contralateral homologue, and only a minority terminates in a part of the torus which contains receptive fields from a distant part of the body surface (Fig. 9; Carr et al., in press). Thus, if the particular delay introduced caused a small cell with input from a distant giant cell to provide a "wrong" response (i.e., interpret a phase lead as a phase lag), it would be overwhelmed by the majority of "correct" responses of other small cells. This concept of a "neuronal democracy" was introduced by Heiligenberg et al. (1978) to explain the behavioral evidence that the JAR is controlled by central interactions of electroreceptive fields on the body surface.

\section{Convergence and the reduction of jitter}

The phase-coding system may derive its remarkable ability to lock its response to a particular phase of the stimulus cycle in part from the neuronal convergence at the levels of the electrosensory lateral line lobe and torus. If we assume that inputs have identical timing, on average, and that they are each subject to stochastic variability of a similar magnitude, then any increase in the number of inputs will serve to decrease the SEM. By increasing the number of receptors that converge upon higherorder cells, the system may thus lower its jitter. While there is extensive precedent for using the SD of the timing of events as a measure of jitter, this value alone does not distinguish between two possible sources of temporal variability: (1) that which arises from small, additive stochastic influences from many sources, and would lead to a quasi-Gaussian distribution in the timing of events; and (2) that which arises from a relatively low-noise stochastic process, subject to occasional, very large perturbations. In the latter case, extremely rare events that were mistimed could so inflate the SD of the distribution that it no longer reliably reflected the "typical" performance of the system. To guard against this eventuality, we examined histograms of the latencies of both phase-coding primary afferents and torus units (see Fig. 7) and found that even the largest SDs reflected jitter in the usual sense, with a quasi-Gaussian distribution of events.

The phase-coding system displays several adaptations that decrease the jitter in its elements and, in addition, increase its immunity to small fluctuations in stimulus intensity. We have shown that a stepwise improvement in coding fidelity occurs from the level of the electrosensory lateral line lobe to the torus. Similar indications of decreasing jitter in the phase-coding system were obtained using measures of the phase-coder field potential (Scheich and Bullock, 1974; Scheich et al., 1973).

The primary afferents from one side of the body terminate in the ipsilateral electrosensory lateral line lobe, where some form gap junctions upon the somata of the spherical cells (Maler, 1979; Maler et al., 1981). Each terminal field contacts one to three spherical cells (Heiligenberg and Dye, 1982; personal observation), while each spherical cell receives input from two to four afferents in the centromedial map (Maler et al., 1981). This suggests that there may be close to the same number of phasecoding afferents as there are spherical cells in the centromedial map-approximately 500. As each afferent divides to terminate in the thrce maps (Heiligenberg and Dyc, 1982), the effective number of afferents is increased further. A second consequence of this three-part division is that the degree of convergence in the other two maps presumably is greater than that seen in the centromedial map, as the total number of spherical cells per map is lower in the two more lateral segments. As the centromedial segment has about 500 spherical cells, the centrolateral has about 170 , and the lateral segment about 90 cells, there must be about five times as many phase-coding afferents per spherical cell in the lateral segment as in the centromedial segment, and three times as many in the centrolateral segment as in the centromedial segment. Thus, spherical cells in the lateral maps would be expected to have larger receptive fields and lower jitter than those of the centromedial map.

In addition to the simple convergence described above, the structure of spherical cells is such as to decrease the probability of a single input causing the cell to fire (Maler et al., 1981). The initial segment is long and thin, and the dense undercoating, presumed to be correlated with spike initiation (Waxman and Quick, 1978), is only found just before the onset of myelination. Maler et al. (1981) proposed that synaptic current in a spherical cell must cross a region of high resistance before reaching the spike initiation segment, and that this may shunt any inputs not arriving in synchrony through the low-resistance gap-junction synapses. Thus, the averaging in a spherical cell is improved beyond that of a Gaussian mean, as it appears to be able to reject inputs whose timing is too far away from the mean of the population of afferents.

Convergence upon the torus giant cells may serve to further reduce the jitter. All three electrosensory lateral line lobe maps converge upon a single somatotopic map in the torus (Carr et al., 1981; Heiligenberg and Bastian, 1984; Maler et al., 1981). It is unknown whether spherical cell axons from all three maps terminate on each giant cell, or whether giant cells are "map selective." For any given region of the body, however, receptive field measurements in the torus did not appear to show great variation in size. Our counts of 760 spherical cells in each electrosensory lateral line lobe and 380 giant cells in the whole torus yield a mean convergence of $4: 1$. Maler (1979) counted 600 spherical cells in each electrosensory lateral line lobe, which would provide a slightly lower convergence of $3: 1$.

The convergence at the level of the electrosensory lateral line lobe and the torus may explain the threefold decrease in jitter, or improvement in accuracy of timing, seen between nerve and torus phase-coders (Fig. 6). About three or four afferents converge on one spherical cell (Maler et al., 1981) and at least three or four spherical cells converge upon one giant cell. Thus, from 9 to 16 phase-coding afferents will converge upon each giant cell; averaging will, in theory, reduce the jitter in the system by $\sqrt{N}$ or three to four times (Calvin, 1983), which is close to the measured value.

Both the nerve-to-spherical cell and spherical cell-to-giant cell synapses are mediated by gap junctions (Maler et al., 1981; Sotelo et al., 1975; Szabo and Fessard, 1974; Szabo et al., 1975; Carr et al., in press). The unusual spike and psp shapes recorded in or close to the giant cell somata suggest that they too act to average their inputs. When the electrotonic psps do not arrive with sufficient synchrony, large psps, not spikes, are recorded. Recordings far from the soma, at stimulus amplitudes insufficient to cause $1: 1$ firing, suggest that these psps do not produce action potentials (Fig. 9).

The above adaptations serve to improve the ability of the system to reflect small temporal modulations. The averaged response of the neuron in Figure $7 B$ reflects the $0.5 \mu$ sec temporal disparity between the two stimuli. The pair of histograms, however, is based upon a sample of approximately 10,000 spikes (5000 each), which corresponds to a total sampling time of approximately $30 \mathrm{sec}$ for a fish with an electric organ discharge frequency of $300 \mathrm{~Hz}$. Mcasurements in thesc fish, however, revealed that the response latency for the detection of a change in the neighbor's frequency, whether higher or lower than the 
fish's own, is not longer than $300 \mathrm{msec}$, even at near-threshold levels of the interfering stimulus. The animal, therefore, needs a sample period of no more than approximately 100 electric organ discharge cycles to determine whether the neighbor's frequency is higher or lower than its own. During this time, the phase difference is modulated from 0 to 400 nsec. Sufficient temporal resolution for the detection of small phase modulations would therefore require parallel sampling of many phasecoding afferent inputs.

The responses of the small cells of lamina VI are fairly jittery (Heiligenberg and Rose, 1985), and we doubt that individual small-cell responses sampled over the reaction time of the animal are sufficient to provide an unambiguous response at modulation amplitudes corresponding to the behavioral threshold. This suggests that cells in other torus laminae, or other nuclei, display higher sensitivity to temporal disparities by sampling inputs from many small cells.

The chain of neurons that control the JAR from its scnsory input to the final motor output may become more and more sensitive to stimulus variables critical for the JAR. Since the pacemaker of the electric organ consists of electrically coupled cells, which fire in strict synchrony (Bennett et al., 1967), the firing of a single pacemaker cell reflects the entire JAR and thus shares its high sensitivity to stimulus variables. It is possible that neurons presynaptic to the pacemaker may not yet be as sensitive as the pacemaker itself, and that the extreme sensitivity at the level of the pacemaker may result statistically from the pooling of inputs from large populations of only moderately sensitive neurons. The jitter or SD of the intervals between electric organ discharge cycles is about 400 nsec in Eigenmannia (Bullock et al., 1975), i.e., the accuracy of the carrier signal is similar to the limits of the resolution of the sensory system.

\section{Sensitivity to amplitude modulations}

Amplitude-coding units of the electrosensory lateral line lobe vigorously follow modulations in amplitude on the order of $1 \%$, and Bastian (1981) has measured response thresholds of approximately $0.2 \%$ in the ELL of the related genus, Apteronotus. By demonstrating that the JAR can be driven by $|\mathrm{S} 2| /|\mathrm{S} 1|$ ratios as small as $0.03 \%$, this study has also shown that Eigenmannia is able to detect relative amplitude modulations of that size. This ability is probably related to electrolocation, where the detection of very small amplitude modulations is a necessary part of the detection of small and distant objects. Bastian (1981) demonstrated an increase in sensitivity to amplitude modulations by a factor of 16 , with the progression from receptors to the ELL-a considerably greater gain than the threefold improvement seen in the phase-coding system.

Detection of small amplitude modulations is not confined to the clcctrosensory system, although electric fish appear to be unusually sensitive. Single unit studies in the inferior colliculi of both bats and rats have demonstrated sensitivity to amplitude modulations below 5\% (Rees and Møller, 1983).

\section{References}

Bastian, J. (1981) Electrolocation. II. The effects of moving objects and other electrical stimuli on the activities of two categories of posterior lateral line lobe cells in Apteronotus albifrons. J. Comp. Physiol. 144: 481-494.

Bastian, J., and W. Heiligenberg (1980a) Phase sensitive midbrain neurons in Eigenmannia: Neural correlates of the jamming avoidance response. Science 209: 828-831.

Bastian, J., and W. Heiligenberg (1980b) Neural correlates of the jamming avoidance response in Eigenmannia. J. Comp. Physiol. 136: 135-152.

Bennett, M. V. L., G. D. Pappas, G. Giminez, and Y. Nakajima (1967) Physiology and ultrastructure of electrotonic junctions. IV. Medullary electromotor nuclei in gymnotoid fish. J. Ncurophys. 30: 236-300.
Bergman, C., W. Nonner, and R. Stampfli (1968) Sustained spontaneous activity of Ranvier nodes induced by combined actions of TEA and lack of calcium. Pflugers Arch. Ges. Physiol. 317: 287-302.

Bullock, T. H. B., K. Behrend, and W. Heiligenberg (1975) Comparison of the jamming avoidance responses in Gymnotoid and Gymnarchid electric fish: A case of convergent evolution of behavior and its sensory basis. J. Comp. Physiol. 103: 97-121.

Bullock, T. H., R. H. Hamstra, and H. Scheich (1972) The Jamming Avoidance Response of high frequency electric fish. I and II. J. Comp. Physiol. 77: 1-48.

Calvin, W. H. (1983) A stone's throw and its launch window: Timing precision and its implications for language and hominid brains. $\mathbf{J}$. Theor. Biol. 104: 121-135.

Carr, C. E., and L. Maler (1985) A Golgi study of the cell types of the dorsal torus semicircularis of the electric fish Eigenmannia: Functional and morphological diversity in the midbrain. J. Comp. Neurol. 235: 207-240.

Carr, C. E., and W. Heiligenberg (1982) Identified phase coder neurons in the electric fish torus. Neurosci. Abstr. 8: 942.

Carr, C. E., L. Maler, W. Heiligenberg, and E. Sas (1981) Laminar organization of the afferent and efferent systems of the torus semicircularis of gymnotiform fish: Morphological substrates for parallel processing in the electrosensory system. J. Comp. Neurol. 203: 649670.

Carr, C. E., L. Maler, and E. Sas (1982) Peripheral organization and central projections of the electrosensory nerves in gymnotiform fish. J. Comp. Neurol. 211: 139-153.

Carr, C. E., B. Taylor, and L. Maler (1983) Ultrastructure of a phasecomparison circuit in the midbrain of the weakly electric fish, Eigenmannia. Neurosci. Abstr. 9: 1028.

Carr, C. E., L. Maler, and B. Taylor (in press) A time comparison circuit in the electric fish midbrain. II. Functional morphology. J. Neurosci.

Enright, J. T. (1970) Stereopsis, visual latency, and three dimensional moving pictures. Am. Sci. 58: 536-545.

Harnischfeger, G. (1980) Brainstem units of echolocating bats code binaural time differences in the microsecond range. Naturwissenschaften 67: 314-316.

Harnischfeger, G., G. Neuwiler, and P. Schlegel (1985) Interaural time and intensity coding in superior olive complex and inferior colliculus of the echolocating bat, Molossus ater. J. Neurophys. 53: 89-109.

Heiligenberg, W., and J. Bastian (1980) The control of Eigenmannia's pacemaker by distributed evaluation of electroreceptive afferences. $J$. Comp. Physiol. 136: 113-133.

Heiligenberg, W., and J. Bastian (1984) The electric sense of weakly electric fish. Annu. Rev. Physiol. 46: 561-583.

Heiligenberg, W., and C. E. Carr (1983) The torus semicircularis of gymnotoid electric fish: The functional organization of a parallel processor. Neurosci. Abstr. 9: 532.

Heiligenberg, W., and J. Dye (1982) Labelling of electroreceptive afferents in a gymnotoid fish by intracellular injection of HRP: The mystery of multiple maps. J. Comp. Physiol. 148: 287-296.

Heiligenberg, W., and B. L. Partridge (1981) How electroreceptors encode jamming avoidance response-eliciting stimulus regimes: Reading trajectories in a phase-amplitude plane. J. Comp. Physiol. 142: 395-408.

Heiligenberg, W., and G. Rose (1985) Phase and amplitude computations in the midbrain of an electric fish: Intracellular studies of neurons participating in the Jamming Avoidance Response (JAR) of Eigenmannia. J. Neurosci. 5: 515-535.

Heiligenberg, W., C. Baker, and J. Matsubara (1978) The Jamming Avoidance Response in Eigenmannia revisited: The structure of a neuronal democracy. J. Comp. Physiol. 127: 267-286.

Hopkins, C. (1976) Stimulus filtering and electroreception: Tuberous electroreceptors in three species of gymnotoid fish. J. Comp. Physiol. 111: 171-208.

Knudsen, E., and M. Konishi (1979) Mechanisms of sound location in the barn owl (Tyto alba). J. Comp. Physiol. 133: 13-21.

Knudsen, E. I., G. G. Blasdel, and M. Konishi (1979) Sound localization by the barn owl (Tyto alba). J. Comp. Physiol. 133: 1-11.

Lit, A. (1949) The magnitude of the Pulfrich stereophenomenon as a function of binocular differences in intensity at various levels of intensity. Am. J. Psychol. 62: 159-181.

Maler, L. (1979) The posterior lateral line lobe of certain gymnotoid fish: Quantitative light microscopy. J. Comp. Neurol. 183: 323-363. Maler, L., T. Finger, and H. J. Karten (1974) Differential projections 
of ordinary lateral line and electroreceptors in the gymnotid fish, Apteronotus albifrons. J. Comp. Neurol. 158: 363-382.

Maler, L., E. Sas, C. E. Carr, and J. Matsubara (1982) Efferent projections of the posterior lateral line lobe in gymnotiform fish. J. Comp. Neurol. 211: 154-164.

Malcr, L., E. Sas, and J. Rogers (1981) The cytology of the posterior lateral line lobe of high frequency weakly electric fish (Gymnotoidei): Dendritic differentiation and synaptic specificity in a simple cortex. J. Comp. Neurol. 195: 87-140.

Mills, A. W. (1958) On the minimal audible angle. J. Acoust. Soc. 30: 237-246.

Mills, A. W. (1972) Auditory localization. In Foundations of Modern Auditory Theory, Vol. II, J. V. Tobias, ed., pp. 303-348, Academic, New York.

Moiseff, A., and M. Konishi (1981) Neuronal and behavioral sensitivity of binaural time differences in the owl. J. Neurosci. $1: 40-48$.

Partridge, B. L., W. Heiligenberg, and J. Matsubara (1981) The neural basis of a sensory filter in the Jamming Avoidance Response: No Grandmother Cells in sight. J. Comp. Physiol. 145: 153-168.

Recs, A., and A. Møller (1983) Responses of neurons in the inferior colliculus of the rat to AM and FM tones. Hearing Res. 10: 301-330.

Rose, G., and W. Heiligenberg (1985) Structure and function of electrosensory neurons in the torus semicircularis of Eigenmannia: Correlations of structure with function. J. Neurosci. 5: 2269-2280.

Scheich, H., and T. H. Bullock (1974) The role of electroreceptors in the animal's life. II. The detection of electric fields from electric organs. In Handbook of Sensory Physiology, Vol. III, Sec. 3, A. Fessard, ed., pp. 201-256, Springer-Verlag, Berlin.

Scheich, H., T. H. Bullock, and R. H. Hamstra (1973) Coding properties of two classes of afferent nerve fibers. High frequency electroreceptors in the electric fish, Eigenmannia. J. Neurophysiol. 36: 3960.

Shumway, C. (1984) Efferent connections of the electrosensory lateral line lobe: An intracellular HRP and lucifer study. Ncurosci. Abstr. 10: 403.

Simmons, J. A. (1979) Perception of echo phase information in bat sonar. Science 204: 1336-1338.
Simmons, J. A., S. A. Kick, B. D. Lawrence, C. Hale, C. Bard, and B. Escudie (1983) Acuity of horizontal angle discrimination by the echolocating bat, Eptesicus fuscus. J. Comp. Physiol. 153: 321-330.

Sotelo, C. M., M. Rethelyi, and T. Szabo (1975) Morphological correlates of electrotonic coupling in the magnocellular mesencephalic nucleus of the weakly electric Gymnotus carapo. J. Neurocytol. 4: $587-607$.

Suga, N. (1982) Functional organization of the auditory cortex. In Cortical Sensory Organization, C. N. Woolsey, ed., pp. 157-218, Humana Press, Clifton, NJ.

Sullivan, W. E., and M. Konishi (1984) Segregation of stimulus phase and intensity coding in the cochlear nucleus of the barn owl. J. Neurosci. 4: 1787-1799.

Szabo, T. (1967) Activity of peripheral and central neurons involved in electroreception. In Lateral Line Detectors, P. Cahn, ed., pp. 295311, Indiana U.P., Bloomington, IN.

Szabo, T., and A. Fessard (1974) Physiology of electroreceptors. In Handbook of Sensory Physiology, Vol. III Pt. 3, A. Fessard, ed., pp. 59-124, Springer-Verlag, Berlin, Heidelberg, New York.

Szabo, T., H. Sakata, and M. Ravaille (1975) An clcctronically coupled pathway in the central nervous system of teleost fish, Gymnotidae and Mormyridae. Brain Res. 95: 459-474.

Takahashi, T., A. Moiseff, and M. Konishi (1984) Time and intensity cues are processed independently in the auditory system of the owl. J. Neurosci. 4: 1781-1786.

Tobias, J. V. (1972) Curious binaural phenomena. In Foundations of Modern Auditory Theory, Vol. II, J. V. Tobias, ed., pp. 465-486, Academic, New York.

Waxman, S. G., and D. C. Quick (1978) Intra-axonal ferric ionferrocyanide staining of nodes of Ranvier and initial segments in central myelinated fibers. Brain Res. 144: 1-10.

Zakon, H. H., and J. H. Meyer (1983) Plasticity of electroreceptor tuning in the weakly electric fish, Sternopygus dariensis. J. Comp. Physiol. 153: 477-487. 